\title{
Source Specific Chemical and Toxicological Profiles of Port- Derived Particulate Matter
}

\author{
N. H. C. EASTON ${ }^{1 *}$, M. J. COOPER ${ }^{1}$, P. S. BRAY ${ }^{1}$, \\ F. M. J. BULOT' ${ }^{2}$, S. J. COX ${ }^{2}$, S. J. OSSONT ${ }^{2}$, \\ G. L. FOSTER ${ }^{1}$, M. LOXHAM ${ }^{3}$ \\ ${ }^{1}$ Ocean and Earth Sciences, Faculty of Environmental and \\ Life Sciences, University of Southampton, Southampton, \\ UK (*correspondence: nhcs1g13@soton.ac.uk) \\ ${ }^{2}$ Faculty of Engineering and Physical Sciences, University of \\ Southampton, Southampton, UK \\ ${ }^{3}$ Clinical and Experimental Sciences, Faculty of Medicine, \\ University of Southampton, Southampton, UK
}

Ambient particulate matter (PM) is associated with ca. 9 million premature deaths per year [1]. Emissions from ships and associated portside activities are major contributors to $\mathrm{PM}$ in port cities, but their composition and toxicology is poorly understood. This is especially important as the maritime sector represents a key source of airborne pollutants, with over $80 \%$ of global trade being transported by sea [2].

A high volume cascade impactor was used to collect coarse $(10-2.5 \mu \mathrm{m})$, fine $(2.5-0.1 \mu \mathrm{m})$ and ultrafine (UF; $<0.1$ $\mu \mathrm{m})$ PM from 5 sites with contrasting activities at the Port of Southampton, UK, including cargo and cruise ship berths, truck movement, and scrap metal processing, and at a nonport site. Elemental and ionic concentrations were determined by inductively coupled plasma mass spectrometry (ICP-MS) and ion chromatography (IC), respectively. Effects of PM on 16HBE bronchial epithelial cell viability (MTS assay) and inflammatory mediator release (ELISA) were also assessed.

PM composition varied by site and size fraction, reflecting local sources. During cruise season, increased V and $\mathrm{Ni}$ concentrations were observed, especially in fine and UF fractions. Following the introduction of sulfur content regulations on shipping fuel, it was found $\mathrm{SO}_{4}{ }^{2-}$ did not correlate with shipping at this port. UFPM collected near cruise ships elicited greatest release of inflammatory mediators from exposed 16HBE cells. Across all samples there was significant association between PM V and $\mathrm{Ni}$ concentrations, and the release of multiple inflammatory mediators, and an inverse association with cell viability.

These results show port-derived PM has source-related elemental profiles, enabling a future source apportionment study. Toxicological results suggest the UF fraction of shipping PM may pose a heightened risk to health.

[1] Burnett et al. (2018), PNAS 115, 9592 - 9597. [2] Murena et al. (2018), Atmospheric Environment 187, 70-83. 